\title{
PEMANFAATAN APLIKASI POWTOON DALAM PEMBUATAN MEDIA PEMBELAJARAN BAGI GURU SMAN 4 KEPAHIANG
}

\author{
Andik Purwanto \\ Pendidikan fisika/Universitas Bengkulu \\ e-mail: andik.purwanto@unib.ac.id \\ Eko Risdianto \\ Pendidikan fisika/Universitas Bengkulu \\ e-mail: eko_risdianto@unib.ac.id \\ Desy Hanisa Putri \\ Pendidikan fisika/Universitas Bengkulu \\ e-mail: desyhanisaputri@gmail.com \\ Fitri Masito \\ Politeknik Penerbangan/Poltekbang Palembang \\ e-mail: fitri.masito@poltekbangplg.ac.id \\ I Gusti Agung Ayu Mas Oka \\ Politeknik Penerbangan/Poltekbang Palembang \\ e-mail: ig_ayumasoka@poltekbangplg.ac.id
}

\begin{abstract}
Abstrak
Di era disrupsi seperti saat ini, dunia pendidikan dituntut mampu membekali para peserta didik dengan ketrampilan abad 21 (21st Century Skills). Guru dan dosen pun harus harus siap menghadapi ketrampilan ini. Guru dan dosen harus memiliki core kompetensi yang kuat, memiliki softskil yaitu : Critical Thingking, kreatif, komunikatif dan koloberatif. Untuk mencapai keterampilan abad 21, trend pembelajaran dan best practices juga harus disesuaikan, salah satunya adalah dengan menggunakan pendekatan model pembelajaran berbasis ICT seperti Media Pembelajaran Berbentuk Video Animasi yang dibuat menggunakan aplikasi PowToon. Kegiatan ini bertujuan untuk (1) mendeskripsikan peningkatan ketrampilan khususnya literasi digital guruguru dalam pembuatan media pembelajaran menggunakan PowToon, sehingga nantinya dapat meningkatkan pemahaman siswa (2) meningkatkan motivasi guru dalam mempergunakan Teknologi Informasi khususnya menggunakan aplikasi PowToon dalam membantu pembelajaran khususnya pada siswa SMAN 4 Kepahiang sehingga dapat memotivasi guru-guru dalam menggunakan inovasi pembelajaran terkini. Metode Kegiatan menggunakan RPA (Participatory Rural Appraisal). Bentuk kegiatan ini berupa pelatihan atau workshop yang di ikuti oleh 33 guru SMAN 4 Kepahiang. Hasil pengabdian ini hampir seluruh guru yang mengikuti kegiatan ini antusias dan dapat menyerap materi yang diberikan dengan baik. Sehingga dapat disimpulkan bahwa kegiatan pelatihan ini berjalan sesuai dengan tujuan yang diinginkan dan dapat ditindakljuti untuk program pengabdian berikutnya.
\end{abstract}

Kata Kunci : Media Pembelajaran, Powtoon, Revolusi Industri 4.0

\begin{abstract}
In this era of disruption, the world of education is required to be able to equip students with 21st Century Skills. Teachers and lecturers must also be prepared to face these skills. Teachers and lecturers must have strong core competencies, have soft skills include: Critical Thinking, creativity, communication, and collaboration. To achieve 21st-century skills, learning trends and best practices
\end{abstract}


Andik Purwanto, Eko Risdianto, Desy Hanisa Putri, Fitri Masito, I Gusti Agung Ayu Mas Oka

PEMANFAATAN APLIKASI POWTOON DALAM PEMBUATAN MEDIA PEMBELAJARAN BAGI GURU

SMAN 4 KEPAHIANG

must also be adjusted, one of which is by using an ICT-based learning model approach such as Learning Media in the form of Animated Videos created using the PowToon application. This activity aims to (1) describe the improvement of skills, especially digital literacy of teachers in making learning media using PowToon, so that later it can improve student understanding (2) increase teacher motivation in using Information Technology, especially using the PowToon application in helping to learn, especially for high school students 4 Kepahiang so that it can motivate teachers to use the latest learning innovations. Method Activities using RPA (Participatory Rural Appraisal) is an approach and method that allows the community to jointly analyze life problems to formulate real plans and policies. The form of this activity is in the form of training or workshops which are attended by 33 teachers of SMAN 4 Kepahiang. From the results of this service, almost all teachers who participated in this activity were enthusiastic and could absorb the material provided well. So it can be concluded that this training activity is running by the desired goals and can be followed up for the next service program.

Keywords : Learning Media, Powtoon, Industrial Revolution 4.0

\section{Pendahuluan}

Revolusi industri yang terjadi di dunia turut mempengaruhi perkembangan pendidikan. Revolusi Industri 4.0 terjadi pada sekitar tahun 2010an melalui rekayasa intelegensia dan internet of thing sebagai tulang punggung pergerakan dan konektivitas manusia dan mesin (Prasetyo \& Trisyanti, 2018). Revolusi ini telah mempersingkat jarak dan waktu, revolusi ini mengedepankan sisi real time (Risdianto, 2019a).

Teknologi informasi pada Era 4.0 telah menjadi basis atau dasar dalam kehidupan manusia tidak terkecuali dalam bidang pendidikan di Indonesia. Di Era 4.0 beberapa hal terjadi menjadi tanpa batas melalui teknologi komputasi dan data yang tidak terbatas, ini dapat terjadi dikarenakan pengaruh dari perkembangan internet dan teknologi digital yang masif sebagai tulang punggung pergerakan dan konektivitas manusia dan mesin. Era ini juga akan mendisrupsi berbagai aktivitas manusia, termasuk di dalamnya bidang ilmu pengetahuan dan teknologi (IPTEK) serta pendidikan tinggi.

Saat ini tengah dilaksanakan langkah langkah strategis oleh Pemerintah Indonesia yang ditetapkan berdasarkan peta jalan Making Indonesia 4.0. Visi penyusunan Making Indonesia 4.0 salah satunya adalah menjadikan Indonesia masuk dalam 10 besar negara yang memiliki perekonomian terkuat di dunia pada tahun 2030 (Satya, 2018). Fokus keahlian bidang Pendidikan abad 21 saat ini meliputi cretivity, critical thingking, communication dan collaboration atau yang dikenal dengan 4Cs. 


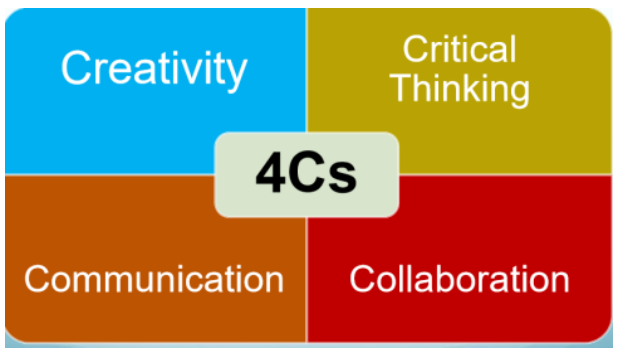

Gambar 1 Ketrampilan Abad 21

(Risdianto, 2019b)

Saat ini, kita berada di era disrupsi dimana dunia pendidikan dituntut mampu membekali para peserta didik dengan ketrampilan abad 21 (21st Century Skills). Kemampuan yang harus dimiliki di di abad 21 ini diantaranya adalah: Leadership, Digital Literacy, Communication, Emotional Intelligence, Entrepreneurship,Global Citizenship , Problem Solving, Team-working. Selain itu, peserta didik, Guru dan dosen juga harus siap menghadapi keterampilan ini. Guru dan dosen harus memiliki core kompetensi yang kuat, memiliki softskil antara lain: Critical Thingking, kreatif, komunikatif dan kolaboratif. Peran guru dan dosen sebagai teladan karakter, menebar passion dan inspiratif. Inilah peran yang tidak dapat digantikan oleh teknologi.

Trend pembelajaran dan best practices harus disesuaikan untuk mencapai keterampilan abad 21, diantaranya adalah dengan menggunakan pendekatan model pembelajaran berbasis ICT seperti Media Pembelajaran Berbentuk Video Animasi yang dibuat menggunakan aplikasi PowToon. Media animasi ini merupakan gabungan antara gambar, tulisan, suara dan animasi yang bergerak, yang dipakai dalam memudahkan seseorang memahami materi (Wulandari et al., 2020).

Dengan adanya media pembelajaran video animasi, guru tidak lagi mengajar berdasarkan buku teks tetapi penyampaian pelajaran dilakukan melalui video animasi (Rosiyanti et al., 2020). Penggunaan media audio visual memegang peran yang sangat penting dalam proses belajar. Audio visual dapat pula menumbuhkan minat siswa dan dapat memberikan hubungan antara isi materi pelajaran dengan dunia nyata (Ariyanto et al., 2018). Oleh sebab itu perlu dibuat sebuah Pengabdian Pelatihan Pemanfaatan Aplikasi PowToon dalam Pembuatan Media Pembelajaran Bagi Guru SMAN 4 Kepahiang dengan tujuan (1) Mendeskripsikan peningkatan ketrampilan khususnya literasi digital guru-guru dalam pembuatan media pembelajaran menggunakan PowToon, sehingga nantinya dapat meningkatkan pemahaman siswa (2) Meningkatkan motivasi guru dalam mempergunakan Teknologi Informasi khususnya menggunakan aplikasi PowToon dalam membantu pembelajaran khususnya pada siswa SMAN 4 Kepahiang sehingga dapat memotivasi guru-guru dalam menggunakan inovasi pembelajaran terkini. Manfaat yang diharapkan dari Pengabdian Pada Masyarakat ini adalah : (1) Menjadikan siswa lebih tertarik dan aktif mengikuti kegiatan pembelajaran melalui media 
Andik Purwanto, Eko Risdianto, Desy Hanisa Putri, Fitri Masito, I Gusti Agung Ayu Mas Oka

PEMANFAATAN APLIKASI POWTOON DALAM PEMBUATAN MEDIA PEMBELAJARAN BAGI GURU

SMAN 4 KEPAHIANG

pembelajaran menggunakan PowToon (2) Meningkatkan pemahaman/penguasaan materi dan kemampuan siswa melalui media pembelajaran menggunakan PowToon (3) Memotivasi Guru agar dapat merancang materi ajar yang kreatif dan inovatif melalui media pembelajaran yang digunakan.

\section{Metode}

Sasaran utama pada kegiatan pengabdian pada masyarakat ini adalah guru-guru di lingkungan SMAN 4 Kepahiang. Pengetahuan yang didapatkan dapat disebarluaskan oleh guru-guru yang lain. Metode Kegiatan menggunakan RPA (Participatory Rural Appraisal) adalah pendekatan dan metode yang memungkinkan masyarakat secara bersama-sama menganalisis masalah kehidupan dalam rangka merumuskan perencanaan dan kebijakan secara nyata. Kegiatan ini dilaksanakan dengan menggunakan pendekatan partisipatif, dan pelatihan. Materi pelatihan dikemas dalam bentuk pelatihan langsung, diskusi dan melalui buku yang disertai video tutorial sehingga diharapkan guruguru dapat mudah untuk memahami tentang cara penggunaan aplikasi PowToon dalam pembuatan Media Pembelajaran Video Animasi. Kegiatan dimulai dengan observasi lapangan sampai kepada pencarian informasi pendukung kelayakan program.

Untuk mengetahui sejauh mana tingkat keberhasilan pengabdian ini, maka pada akhir kegiatan penerapan Ipteks akan dilakukan evaluasi dengan cara melihat apakah pelatihan pembuatan media pembelajaran animasi video menggunakan PowToon dapat meningkatkan pengetahuan guruguru di SMAN 4 Kepahiang tentang pembuatan media pembelajaran video animasi pada materi ajar yang diampu. Jika guru tersebut telah memahami dan mampu mengaplikasikan program yang digunakan dengan baik dan lancar dalam membuat media pembelajaran berupa video animasi, maka dapat disimpulkan bahwa kegiatan ini dapat dikembangkan dan manfaatnya dapat dirasakan langsung oleh guru-guru SMAN 4 Kepahiang sebagai khalayak sasaran.

\section{Hasil dan Pembahasan}

Pelaksanaan pengabdian masyarakat tentang "Pemanfaatan Aplikasi Powtoon Dalam Pembuatan Media Pembelajaran Bagi Guru SMAN 4 Kepahiang” telah terlaksana dengan baik. Kegiatan ini dilaksanakan pada 22 Maret 2021. Kegiatan ini di ikuti oleh 33 guru di SMAN 4 Kepahiang. Kegiatan ini sangat antusias diikuti dalam upaya menyongsong Era Revolusi Industri. Materi yang disajikan adalah tentang pembuatan media pembelajaran video animasi menggunakan PowToon.

Penggunaan alat bantu belajar atau media pembelajaran merupakan bagian yang tidak bisa dipisahkan dari proses pembelajaran dan merupakan suatu bentuk integrasi terhadap metode belajar 
Andik Purwanto, Eko Risdianto, Desy Hanisa Putri, Fitri Masito, I Gusti Agung Ayu Mas Oka

PEMANFAATAN APLIKASI POWTOON DALAM PEMBUATAN MEDIA PEMBELAJARAN BAGI GURU SMAN 4 KEPAHIANG

yang dipakai. Media pembelajaran banyak macamnya dari yang berbentuk CD pembelajaran, $E$ Learning dan tutorial interaktif (Risdianto, 2010). Namun pada kenyataannya, media-media yang digunakan tersebut masih kurang memenuhi standar pembelajaran yang ada dikarenakan bersifat bacaan saja yang bisa dibilang kurang menarik untuk dipelajari oleh siswa sehingga membuat proses pembelajaran membosankan. Padahal media pembelajaran merupakan komponen yang dapat membangkitkan motivasi dan minat siswa (Risdianto et al., 2021). Maka dari itu, dalam pembelajaran dibutuhkan inovasi media pembelajaran yang efektif, efisien, menarik, mudah dibuat dan dekat dengan kehidupan sehari-hari siswa (Peranti et al., 2019).

Aplikasi PowToon merupakan media berbasis AudioVisual yang berupa layanan online untuk membuat sebuah paparan yang memiliki fitur animasi sangat menarik diantaranya animasi tulisan tangan, animasi kartun, dan efek transisi yang lebih hidup serta pengaturan timeline yang sangat mudah (Rosiyanti et al., 2020).

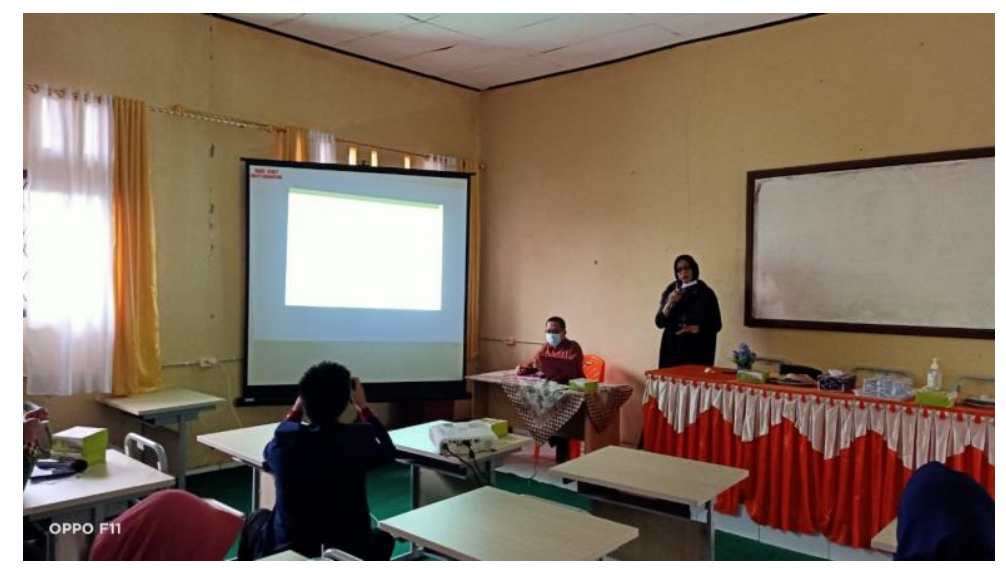

Gambar 2 Pengenalan Aplikasi PowToon

PowToon sangat cocok untuk dikembangkan sebagai media pembelajaran, selain menarik PowToon juga tidak perlu diinstal di komputer dikarenakan aplikasi ini dibuat secara online di laman www.PowToon.com. Meskipun dibuat secara online, namun hasilnya dapat dipergunakan secara offline baik dalam bentuk presentasi maupun dalam bentuk pdf (Nurdiansyah et al., 2018). 


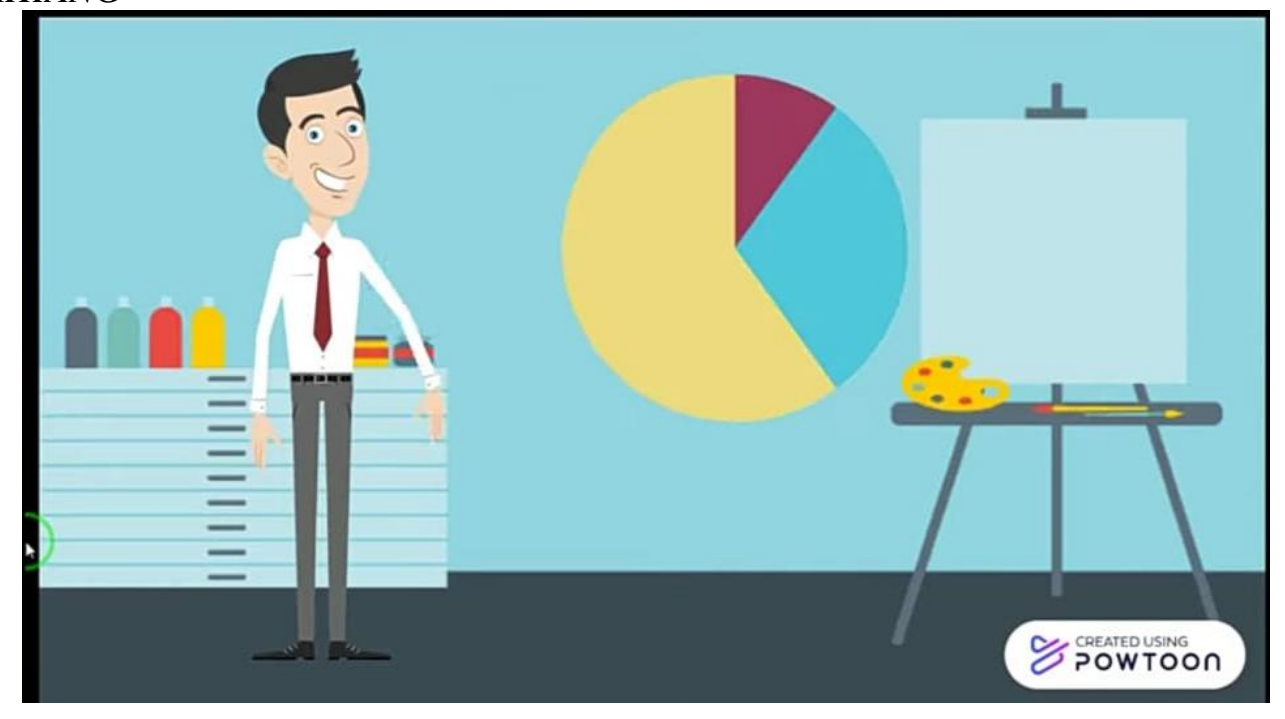

Gambar 3 Contoh Animasi Hasil Powtoon

Materi ini sangat baru bagi peserta pelatihan dan para peserta sangat antusias untuk menerapkan dalam pembelajaran. Indikator ketertarikan dalam materi ini adalah permintaan kembali dari peserta dan sekolah untuk kembali memberikan pelatihan lanjutan tentang pembuatan media pembelajaran video animasi ini.

Dalam proses pelatihan yang di ikuti oleh guru-guru di SMAN 4 Kepahiang menunjukkan hampir semua peserta dapat mengikuti seluruh kegiatan dan mempraktekkan materi yang disampaikan dan diimplementasikan pada mata pelajaran yang diampu oleh peserta guru tersebut. Terdapat beberapa kendala tentang pengoperasian yang dijumpai oleh beberapa peserta, namun dapat diatasi dengan memberikan pendampingan yang komprehensif. Dari pelatihan ini dituntut kepada peserta untuk dapat langsung di implementasikan agar pengetahuan yang telah di dapat selama kegiatan pengabdian dapat terus melekat dan disebarkan baik ke teman sejawat ataupun sekolah yang lain.

\section{Kesimpulan}

Kegiatan pengabdian pada masyarakat tentang pelatihan Pembuatan Media Pembelajaran menggunakan PowToon di SMAN 4 Kepahiang telah mampu memberikan wawasan kepada guruguru tentang pemanfaatan teknologi dalam pembuatan media pembelajaran. Kegiatan ini juga telah memberikan motivasi kepada guru guru untuk lebih meningkatkan kemampuan mereka dalam membuat media pembelajaran yang lebih menarik dan inovatif. 


\section{Daftar Pustaka}

Ariyanto, R., Kantun, S., \& Sukidin, S. (2018). Penggunaan Media Powtoon Untuk Meningkatkan Minat Dan Hasil Belajar Siswa Pada Kompetensi Dasar Mendeskripsikan Pelaku-Pelaku Ekonomi Dalam Sistem Perekonomian Indonesia. Jurnal Pendidikan Ekonomi: Jurnal Ilmiah Ilmu Pendidikan, Ilmu Ekonomi Dan Ilmu Sosial, 12(1), 122. https://doi.org/10.19184/jpe.v12i1.7622

Nurdiansyah, E., Faisal, E. El, \& Sulkipani, S. (2018). Pengembangan media pembelajaran berbasis PowToon pada perkuliahan Pendidikan Kewarganegaraan. Jurnal Civics: Media Kajian Kewarganegaraan, 15(1), 1-8. https://doi.org/10.21831/jc.v15i1.16875

Peranti, Purwanto, A., \& Risdianto, E. (2019). Pengembangan Media Pembelajaran Permainan Mofin ( Monopoli Fisika Sains ) Pada Siswa Sma Kelas X. Jurnal Kumparan Fisika, 2(1), 41-47.

Prasetyo, B., \& Trisyanti, U. (2018). Revolusi Industri 4.0 Dan Tantangan Perubahan Sosial. Prosiding SEMATEKSOS 3 "Strategi Pembangunan Nasional MenghadapiRevolusiIndustri 4.0."

Risdianto, E. (2010). Pengembangan Multimedia Interaktif (MPI) pada Praktikum Fisika Dasar I. $\operatorname{VI}(2), 9-16$.

Risdianto, E. (2019a). Analisis Pendidikan Indonesia di Era Revolusi Industri 4.0. Academia.Edu.

Risdianto, E. (2019b). Kepemimpinan Dalam Dunia Pendidikan Di Indonesia di Era Revolusi Industri 4.0. 1-12.

Risdianto, E., Syarkowi, A., \& Jumiarni, D. (2021). Kajian dan Riset Dalam Teknologi Pembelajaran Analisis Data Respon Mahasiswa Terhadap Matakuliah Ilmu Lingkungan Menggunakan. 8(1), 47-57. https://doi.org/10.17977/um031v8i12021p047

Rosiyanti, H., Eminita, V., \& Riski, R. (2020). Desain Media Pembelajaran Geometri Ruang Berbasis Powtoon. FIBONACCI: Jurnal Pendidikan Matematika Dan Matematika, 6(1), 77-86. https://dx.doi.org/10.24853/fbc.6.1.77-86.

Satya, V. E. (2018). Strategi Indonesia Menghadapi Industri 4.0.

Wulandari, Y., Ruhiat, Y., \& Nulhakim, L. (2020). Pengembangan Media Video Berbasis Powtoon pada Mata Pelajaran IPA di Kelas V. Jurnal Pendidikan Sains Indonesia (Indonesian Journal of Science Education), 8(2), 269-279. https://doi.org/10.24815/jpsi.v8i2.16835 